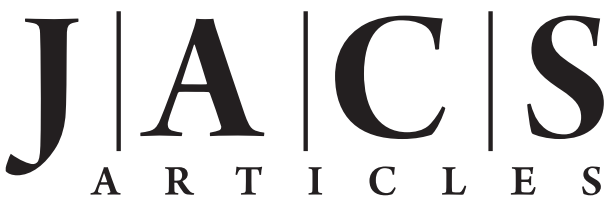

Published on Web 02/19/2010

\title{
Silver Ion Incorporation and Nanoparticle Formation inside the Cavity of Pyrococcus furiosus Ferritin: Structural and Size-Distribution Analyses
}

\author{
Oksana Kasyutich, ${ }^{\dagger}$ Andrea llari, ${ }^{,, \ddagger}$ Annarita Fiorillo, ${ }^{\S, l}$ Dragomir Tatchev, ${ }^{\perp, \#}$ \\ Armin Hoell, ${ }^{\perp}$ and Pierpaolo Ceci ${ }^{*, \neq, \nabla}$ \\ University of Bristol, Physics Department, HH Wills Physics Laboratory, Tyndall Avenues, \\ Bristol, BS8 1TL, U.K., CNR Institute of Molecular Biology and Pathology, Department of \\ Biochemical Sciences, "Sapienza", University of Rome, P.le Aldo Moro 5, 00185 Rome, Italy, \\ Department of Biochemical Sciences "Rossi-Fanelli", "Sapienza", University of Rome, Italy, \\ Dipartimento di Scienze e Tecnologie Biomediche, Universita degli Studi Dell'Aquila, Italy, \\ Helmholtz-Zentrum Berlin für Materialien und Energie GmbH, Albert-Einstein-Str. 15, \\ 12489 Berlin, Germany, Institute of Physical Chemistry, BAS, Acad. G. Bonchev Str. bl. 11, \\ 1113 Sofia, Bulgaria, and MoLiRom s.r.l., Via Carlo Bartolomeo Piazza 8, 00161 Rome, Italy
}

Received December 28, 2009; E-mail: pierpaolo.ceci@uniroma1.it; andrea.ilari@uniroma1.it

\begin{abstract}
Highly symmetrical protein cage architectures from three different iron storage proteins, heavy and light human ferritin chains (HuHFt and HuLFt) and ferritin from the hyperthemophilic bacterium Pyrococcus furiosus (PfFt), have been used as models for understanding the molecular basis of silver ion deposition and metal core formation inside the protein cavity. Biomineralization using protein cavities is an important issue for the fabrication of biometamaterials under mild synthetic conditions. Silver nanoparticles (AgNPs) were produced with high yields within PfFt but not within HuHFt and HuLFt. To explain the molecular basis of silver incorporation, the X-ray crystal structure of Ag-containing PfFt has been solved. This is the first structure of a silver containing ferritin reported to date, and it revealed the presence of specific binding and nucleation sites of $\mathrm{Ag}(\mathrm{I})$ that are not conserved in other ferritin templates. The AgNP encapsulated by PfFt were further characterized by the combined use of different physical-chemical techniques. These showed that the AgNPs are endowed with a narrow size distribution $(2.1 \pm 0.4 \mathrm{~nm})$, high stability in water solution at millimolar concentration, and high thermal stability. These properties make the AgNP obtained within PftFt exploitable for a range of applications, in fields as diverse as catalysis in water, preparation of metamaterials, and in vivo diagnosis and antibacterial or tumor therapy.
\end{abstract}

\section{Introduction}

Nanosized particles have elicited much attention in recent years for their distinctly different chemical and physical properties relative to those of ionic and bulk material. ${ }^{1-4}$ Among the various metal nanoparticles, gold and silver ones are of special interest due to their unique optical and electrical properties, as well as for their potential biomedical applications. ${ }^{4-6}$

\footnotetext{
University of Bristol.

$\doteqdot$ CNR Institute of Molecular Biology and Pathology, Department of Biochemical Sciences, "Sapienza", University of Rome.

§ Department of Biochemical Sciences "Rossi-Fanelli", "Sapienza", University of Rome.

"Universita degli Studi Dell'Aquila.

${ }^{\perp}$ Helmholtz-Zentrum Berlin für Materialien und Energie $\mathrm{GmbH}$.

\# BAS.

$\nabla$ MoLiRom s.r.l.

(1) Gu, Q. F.; Krauss, G.; Steurer, W.; Gramm, F.; Cervellino, A. Phys. Rev. Lett. 2008, 100, 045502.

(2) Cushing, B. L.; Kolesnichenko, V. L.; O'Connor, C. J. Chem. Rev 2004, 104, 3893.

(3) Elnathan, R.; Kantaev, R.; Patolsky, F. Nano Lett. 2008, 8, 3964.

(4) Lessard-Viger, M.; Rioux, M.; Rainville, L.; Boudreau, D. Nano Lett. 2009, 9, 3066.

(5) Templeton, A. C.; Cliffel, D. E.; Murray, R. W. J. Am. Chem. Soc. 1999, $121,7081$.

(6) Evanoff, D. D.; Chumanov, G. Chem. Phys. Chem. 2005, 6, 1221.
}

In fact, silver nanoparticles (AgNPs) are characterized by superior catalytic activity and better enhancement factors for surface enhanced Raman scattering (SERS) $)^{6-8}$ and are known to exhibit antimicrobial/antiviral properties. ${ }^{9}$ Recently, Kemp et al. ${ }^{10}$ reported a potential application of silver NPs in angiogenesis modulation and Dhar et al. ${ }^{11}$ used gold NPs for cisplatin delivery to cancer cells.

However, the high reactivity of AgNPs compared for example to gold nanoparticles raises practical difficulties in the preparation of highly homogeneous materials that are stable in water solutions. ${ }^{12}$ Stability and homogeneity are two key issues for several applications of silver nanoparticles, ${ }^{12}$ and previous studies have shown that AgNPs maintain adequate solution

(7) Shen, X. S.; Wang, G. Z.; Hong, X.; Zhu, W. Phys. Chem. Chem. Phys. 2009, 11, 7450.

(8) Jabeen, S.; Dines, T. J.; Withnall, R.; Leharne, S. A.; Chowdhry, B. Z. Phys. Chem. Chem. Phys. 2009, 11, 7476.

(9) Hu, J.; Zhao, B.; Xu, W.; Li, B.; Fan, Y. Acta Part A 2002, 58, 2827.

(10) Kemp, M. M.; Kumar, A.; Mousa, S.; Dyskin, E.; Yalcin, M.; Ajayan, P.; Linhardt, R. J.; Mousa, S. A. Nanotechnology 2009, 45, 455104.

(11) Dhar, S.; Daniel, W. L.; Giljohann, D. A.; Mirkin, C. A.; Lippard, S. J. J. Am. Chem. Soc. 2009, 131, 14652.

(12) Nair, L. S.; Laurencin, C. T. J. Biomed. Nanotechnol. 2007, 3, 301. 
stability at submicromolar levels but not at millimolar ones and that a narrow size distribution of AgNPs is difficult to obtain. ${ }^{13,14}$

In this scenario, the use of protein cages to direct the synthesis of inorganic materials appears to be attractive in the field of nanomaterials science. Protein cages are three-dimensional selfassemblies of highly similar or identical subunits, almost spherical in shape, which enclose a central cavity that is used for the physiological deposition of different materials (e.g., nucleic acids in viral capsids or ferric hydroxide micelles in ferritins). ${ }^{15}$ Therefore, the protein cage can be viewed as a nanoreactor that provides an environment shielded from bulk solution where chemical reactions take place. ${ }^{15-17}$ Importantly, the protein surface is amenable to both genetic and chemical manipulation to impart specific functionalities by design. ${ }^{18-20}$ In fact, chemical derivatization of amino acid side chains on the surface of the molecule could be readily achievable due to the presence of accessible amino, thiol, and carboxyl residues on the protein surfaces. ${ }^{18-21}$

Ferritin is one of the most widely studied proteins with a cage-like structure. ${ }^{22}$ Apo-ferritin, the highly symmetrical protein moiety, consists of 24 subunits that self-assemble into a shell-like molecule endowed with 432 symmetry (molecular mass $\sim 500 \mathrm{kDa}$; external and internal diameters: 12 and $8 \mathrm{~nm}$ ) designed to oxidize and store iron as a microcrystalline hydrated ferric oxide particle. The subunits related by 3- and 4-fold symmetry form at their junction pores that traverse the protein shell so as to allow the passage of ions and small molecules. The 3-fold pores are hydrophilic, being lined with negatively charged residues, and are involved in the uptake of $\mathrm{Fe}(\mathrm{II})$ ions. Iron in particular is guided to the 3 -fold pores by a negative electrostatic gradient, enters the channels, and reaches specific catalytic sites, named the ferroxidase sites, where it is oxidized by molecular oxygen. ${ }^{23,24} \mathrm{Fe}$ (III) thus produced moves to the protein cavity where the iron core nucleates and grows at specific iron binding/nucleation sites to encompass up to 4000 iron atoms. All animal ferritins are assembled from two subunit types, the heavy ( $\mathrm{H}$ chain; $21 \mathrm{kDa}$ ) and light chains (L chain; $20 \mathrm{kDa}$ ); $\mathrm{H}$ chains contain the catalytic centers and are more abundant in tissues with an active iron metabolism. L chains contain many nucleation sites and are more abundant in iron storage tissues like the spleen (horse spleen ferritin, for example contains $\sim 15 \%$ $\mathrm{H}$ and $\sim 85 \% \mathrm{~L}$ chains). In contrast, bacterial ferritins contain a single subunit type that resembles the $\mathrm{H}$ chains. ${ }^{23,24}$

(13) Esumi, K.; Suzuki, A.; Yamahira, A.; Torigoe, K. Langmuir 2000, 16, 2604.

(14) Lok, C. N.; Ho, C. M.; Chen, R.; He, Q. Y.; Yiu, W. Y.; Sun, H.; Tam, P. K.; Chiu, J. F.; Che, C. M. J. Biol. Inorg. Chem. 2007, 12, 527.

(15) Heddle, J. G. Nanotechnol. Sci. Appl. 2008, 1, 67.

(16) de la Escosura, A.; Nolte, R. J. M.; Cornelissen, J. J. L. M. J. Mater. Chem. 2009, 19, 2274.

(17) Lee, L. A.; Wang, Q. Nanomedicine 2006, 2, 137.

(18) Zeng, Q.; Li, T.; Cash, B.; Li, S.; Xie, F.; Wang, Q. Chem. Commun. 2007, 14, 1453 .

(19) Uchida, M.; Flenniken, M. L.; Allen, M.; Willits, D. A.; Crowley, B. E.; Brumfield, S.; Willis, A. F.; Jackiw, L.; Jutila, M.; Young, M. J.; Douglas, T. J. Am. Chem. Soc. 2006, 128, 16626.

(20) Kang, S.; Suci, P. A.; Broomell, C. C.; Iwahori, K.; Kobayashi, M.; Yamashita, I.; Young, M. J.; Douglas, T. Nano Lett. 2009, 9, 2360

(21) Kang, S.; Oltrogge, L. M.; Broomell, C. C.; Liepold, L. O.; Prevelige, P. E.; Young, M.; Douglas, T. J. Am. Chem. Soc. 2008, 130, 16527.

(22) Harrison, P. M.; Arosio, P. Biochim. Biophys. Acta 1996, 275, 161

(23) Wade, V. J.; Levi, S.; Arosio, P.; Treffry, A.; Harrison, P. M.; Mann, S. J. Mol. Biol. 1991, 221, 1443.

(24) Chiancone, E.; Ceci, P.; Ilari, A.; Ribacchi, F.; Stefanini, S. Biometals 2004, 17, 197.
The unique template structure of apo-ferritin and ferritin-like proteins has been used to advantage for the synthesis of a variety of new, nonphysiological mineral cores within the protein shell. Materials such as $\mathrm{Fe}_{3} \mathrm{O}_{4}, \mathrm{Co}_{3} \mathrm{O}_{4}, \mathrm{Mn}_{3} \mathrm{O}_{4}, \mathrm{Pt}, \mathrm{CoPt}, \mathrm{Pd}, \mathrm{CdS}$, $\mathrm{CdSe}, \mathrm{ZnSe}, \mathrm{CaCO}_{3}, \mathrm{SrCO}_{3}$, or $\mathrm{BaCO}_{3}$ have been produced and characterized in different ferritin templates. ${ }^{25-31}$ So far, nanoparticles of noble metals such as gold and silver have been incorporated inside the ferritin cages with very low yields in terms of a metal incorporated/added ratio $(\sim 20-40 \%){ }^{32-35}$ Furthermore, in spite of being of extraordinary importance for future developments, detailed studies on metal ion deposition and metal core formation processes for metals different from iron are rare. Recently, an elegant paper by Ueno et al. ${ }^{36}$ described the processes occurring during Pd(II) ion accumulations inside the horse L-ferritin (HoLFt) cavity. They identified a series of Pd(II) binding sites inside the cavity and suggested that one Cys residue plays a crucial role for coordination to Pd(II) ions. Furthermore, the narrow size distribution of Pd NPs formed in HoLFt was ascribed to a limited number of nucleation sites on the internal protein surface.

In more general terms, the overall data presented in the literature suggest that two parameters must be taken into account to obtain an efficient metal incorporation and a narrow size distribution of the metal nanoparticles formed inside the cavity of ferritin and ferritin-like proteins, namely the external/internal charges distribution ${ }^{37-39}$ and the type and number of metal binding/nucleation sites. ${ }^{36}$

On the basis of these data we focused our attention on the ferritin from the hyperthermophilic archaeon Pyrococcus furiosus (PfFt), a protein characterized by a distinctive charge distribution as apparent from the X-ray crystal structures (see Supporting Information) and a fewer number of iron nucleation sites with respect to other known ferritins, as suggested by sequence comparisons. ${ }^{22,40}$ Indeed, previous studies have shown that residues Glu53, Glu56, Glu57, Glu60, and Glu63 (human L-chain) and Glu57, Glu60, and Glu63 (human H-chain) are mainly responsible for binding/nucleation of the iron oxide mineral. ${ }^{41}$ In PfFt, these acidic patches contain less acidic amino

(25) Meldrum, F. C.; Douglas, T.; Levi, S.; Arosio, P.; Mann, S. J. Inorg. Biochem. 1995, 58, 59.

(26) Douglas, T.; Dickson, D. P.; Betteridge, S.; Charnock, J.; Garner, C. D.; Mann, S. Science 1995, 269, 54.

(27) Li, M.; Viravaidya, C.; Mann, S. Small 2007, 3, 1477.

(28) Ueno, T.; Suzuki, M.; Goto, T.; Matsumoto, T.; Nagayama, K.; Watanabe, Y. Angew. Chem., Int. Ed. 2004, 43, 2527.

(29) Kasyutich, O.; Sarua, A.; Schwarzacher, W. J. Phys. D: Appl. Phys. 2008, 41, 134022.

(30) Yoshimura, H. Colloids Surf., A 2006, 282-283, 464.

(31) Prastaro, A.; Ceci, P.; Chiancone, E.; Boffi, A.; Cirilli, R.; Colone, M.; Fabrizi, G.; Stringaro, A.; Cacchi, S. Green Chem. 2009, 11, 1929.

(32) Zhang, L.; Swift, J.; Butts, C. A.; Yerubandi, V.; Dmochowski, I. J. J. Inorg. Biochem. 2007, 101, 1719.

(33) Domínguez-Vera, J. M.; Gálvez, N.; Sánchez, P.; Mota, A. J.; Trasobares, S.; Hernández, J. C.; Calvino, J. J. Eur. J. Inorg. Chem. 2007, 30, 4823.

(34) Kramer, R. M.; Li, C.; Carter, D. C.; Stone, M. O.; Naik, R. R. J. Am. Chem. Soc. 2004, 126, 13282.

(35) Butts, C. A.; Swift, J.; Kang, S. G.; Di Costanzo, L.; Christianson, D. W.; Saven, J. G.; Dmochowski, I. J. Biochemistry 2008, 47, 12729.

(36) Ueno, T.; Abe, M.; Hirata, K.; Abe, S.; Suzuki, M.; Shimizu, N.; Yamamoto, M.; Takata, M.; Watanabe, Y. J. Am. Chem. Soc. 2009, 131, 5094.

(37) Douglas, T.; Ripoll, D. R. Protein Sci. 1998, 7, 1083.

(38) Takahashi, T.; Kuyucak, S. Biophys. J. 2003, 84, 2256.

(39) Bellapadrona, G.; Stefanini, S.; Zamparelli, C.; Theil, E. C.; Chiancone, E. J. Biol. Chem. 2009, 284, 19101.

(40) Tatur, J.; Hagen, W. R.; Matias, P. M. J. Biol. Inorg. Chem. 2007, 12,615 .

(41) Juan, S. H.; Aust, S. D. Arch. Biochem. Biophys. 1998, 350, 259. 
Scheme 1. Formation of Silver Nanoparticles inside the $8 \mathrm{~nm}$ PfFt Cavity ${ }^{a}$
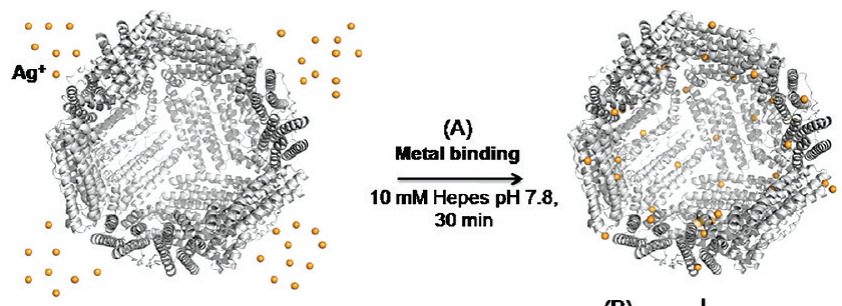

.

(B)
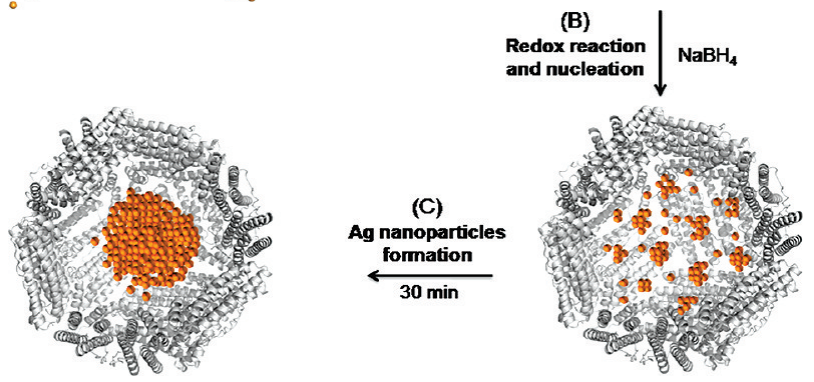

${ }^{a}$ Silver ions (in yellow) access the cavity through symmetrically related pores that cross the protein cage and bind to the binding/nucleation centers at the internal surface. Four subunits were removed to display the protein cavity. Pymol-generated images. Upper-right: Ag(I)-containing PfFt structure (PDB ID: $2 \times 17$ ). All other images were generated from the apo-PfFt structure (PDB ID: 2JD7) by manually adding silver ions for clarity.

acid residues as apparent from the X-ray structures and multiple sequence alignment shown in Figures S2 and S5, respectively (Supporting Information). In the present work we have investigated the ability of PfFt to successfully encapsulate homogeneous AgNPs, in comparison to the commonly used human $\mathrm{H}$ and $\mathrm{L}$ ferritin homopolymers (HuHFt and HuLFt).

The use of PfFt resulted in the simple and efficient synthesis of silver nanoparticles (Scheme 1) characterized by a narrow size distribution $(2.1 \pm 0.4 \mathrm{~nm})$, high stability in water solution at millimolar particle concentrations, and high thermal stability (up to $\sim 90{ }^{\circ} \mathrm{C}$ ). The preparation of AgNPs, conducted in parallel using recombinant HuHFt and HuLFt, could not be achieved, thus highlighting the unique efficiency of PfFt in comparison with the other ferritins studied. To further characterize the AgNP-PfFt system, we performed small-angle X-ray scattering and iron incorporation experiments. These showed that the AgNPs are attached to the shell wall inside the protein cavity. Additionally, silver incorporation on PfFt samples preincorporated with 24 or $48 \mathrm{Fe}$ (III) was significantly reduced, indicating that the two metals compete for protein binding/nucleation.

To elucidate the mechanism of silver incorporation by PfFt we determined the three-dimensional structure of $\mathrm{Ag}(\mathrm{I})$-containing PfFt by X-ray crystallography. This structure is of interest not only because it is the first time that a Ag-ferritin crystal structure is reported but also because it provides essential information on the biomineralization process occurring in PfFt. We identified two different metal binding/nucleation sites. The first site is localized on the cavity surface close to the previously reported iron-binding site $\mathrm{C},{ }^{40}$ and the other site at the 4-fold pore. Both these sites comprise methionine residues, a distinctive feature with respect to all previously characterized ferritin metal binding sites, which suggests that these residues play a crucial role for efficient silver incorporation.

The data reported here are of importance both in unveiling the molecular basis of the observed high metal incorporation efficiency of PfFt protein and the narrow size distribution of
AgNPs produced and in making advances toward the rational design and engineering of optimized ferritin templates.

\section{Results and Discussion}

Preparation of Ferritin Containing $\operatorname{Ag}(\mathrm{I})$ and $\operatorname{Ag}(0)$ and Kinetic Analyses. Silver nanoparticles were prepared at room temperature and $\mathrm{pH} 7.8$ by addition of $\mathrm{AgNO}_{3}$ to the ferritin solutions (Ag/protein oligomer molar ratio 400:1) under stirring and subsequent reduction of the silver ions with $\mathrm{NaBH}_{4}$ (1 equiv per $2 \mathrm{Ag}$ atoms). After further stirring for $30 \mathrm{~min}$, the solution was centrifuged, dialyzed, and concentrated using centrifugal filter devices. The $\mathrm{NaBH}_{4}$ step was omitted for the preparation of PfFt containing $\operatorname{Ag}(\mathrm{I})$. These conditions were chosen because they allowed us to obtain the highest metal incorporated/added ratio.

When PfFt was used as the protein cage, this procedure yielded AgNPs with the typical absorption band around 420 $\mathrm{nm}$ due to the surface plasmon resonance (SPR) of Ag particles of at least $0.5-1 \mathrm{~nm}$ in diameter (Figure 1) and no precipitation was observed after the centrifugation step. Time progression of the reaction was monitored collecting UV-visible spectra of the Ag-containing PfFt sample. The reaction rate is not constant in time, as is often the case for complex processes involving nucleation, particles rearrangements, and growth. Figure 1A,B show that the typical plasmonic band appeared immediately (within the first $40 \mathrm{~s}$ ) after the addition of $\mathrm{NaBH}_{4}$ in the $400 \mathrm{~nm}$ region, strongly suggesting that the production of small nuclei of $\operatorname{Ag}(0)$ has taken place. After a lag phase of $\sim 60 \mathrm{~s}$, the absorption band gradually increased and shifted to 410-420 nm, assuming a sigmoid shape that is typical of cooperative phenomena (Figure 1A,B) and is associated with the formation of larger $\operatorname{Ag}(0)$ particles. Taken together, these two kinetic features, namely the lag and sigmoid phases, strongly suggest that the final silver nanoparticle product is formed due to the rearrangement and association of the small nuclei during the 40-200 s phase (Figure 1 and Scheme 1).

In contrast, when HuHFt and HuLFt were used, a massive bulk precipitation of the material occurred after addition of $\mathrm{AgNO}_{3}$ or $\mathrm{NaBH}_{4}$, respectively, indicating that these ferritin templates are not suitable for the synthesis of AgNPs. Bulk precipitation occurred also in the control reaction performed in the absence of protein.

Characterization of AgNPs-Containing PfFt. The AgNPs obtained with PfFt were characterized first by size exclusion gel filtration chromatography experiments to establish whether the nanoparticles were enclosed within the protein cage. After silver incorporation PfFt elutes like the apoprotein, suggesting that this process does not significantly affect the overall protein structure and assembly, and the elution pattern (Figure 1C) shows coelution of the protein moiety $(280 \mathrm{~nm})$ and the silver cluster $(405 \mathrm{~nm})$, proving the composite nature of the material and indicating that practically all AgNPs ( $\sim 95 \%$ on the basis of the integration area calculated for the elution peaks, using the software UNICORN 5.01, GE Healthcare) are sequestered within the protein cage. Accordingly, the amount of silver incorporated in the PfFt cavity was estimated to be $380 \pm 15$ atoms, on the basis of graphite furnace atomic absorption spectrometry (GFAAS) and quantitative protein assays. It is important to highlight that the formation of Ag-NPs in PfFt was an extremely reproducible process, and over 50 synthetic reactions were achieved with essentially the same result.

From the perspective of possible applications of these bionanocomposites, it is noteworthy that the elution profile of 
A

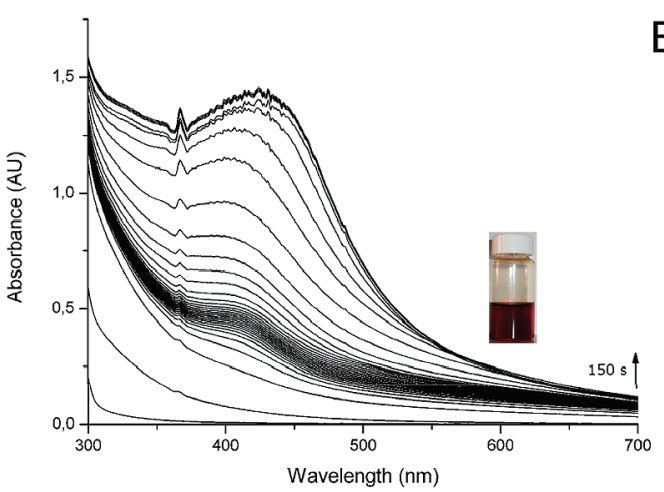

C

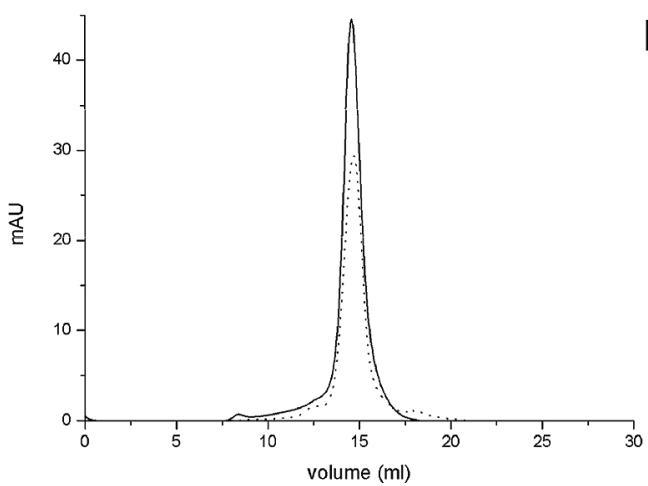

B

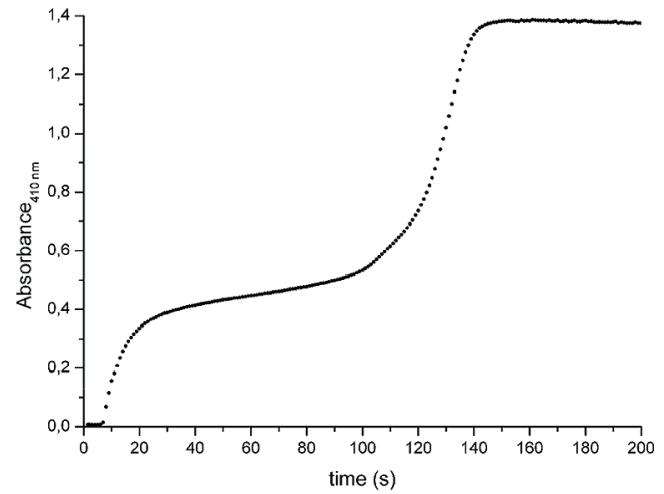

D

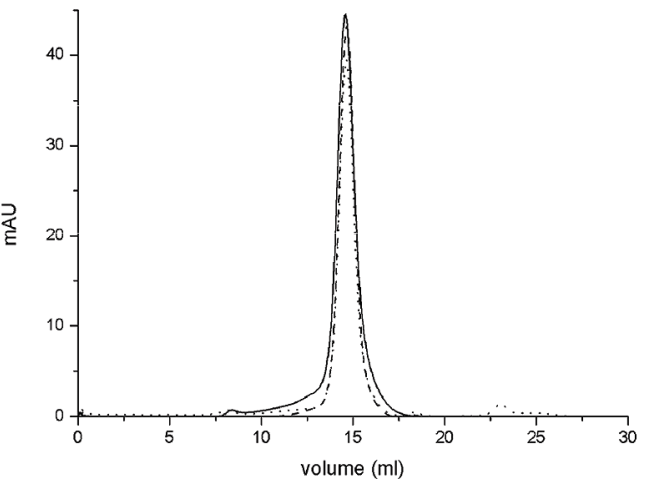

Figure 1. Time-dependent UV-visible absorption spectra and gel-filtration elution profiles of AgNP-containing PfFt. (A) The UV-visible spectra during AgNPs formation were recorded every $1.0 \mathrm{~s}$ following the addition of the reductant and shown every $5.0 \mathrm{~s}$ for clarity. The inset depicts the reddish-brown solution of Ag-PfFt. (B) The kinetic traces were measured at $410 \mathrm{~nm}$, the wavelength at which formation of the silver core can be monitored. $\mathrm{NaBH}_{4}$ was added after $5.0 \mathrm{~s}$. (C) PfFt before ( $280 \mathrm{~nm}$, dotted line) and after silver incorporation (405 nm, solid line). (D) Ag-PfFt before and after heating at 80 or 90 ${ }^{\circ} \mathrm{C}$ for $15 \mathrm{~min}$ (405 nm, before heating: solid line; after heating at 80 or $90{ }^{\circ} \mathrm{C}$ : dashed and dotted lines, respectively).

Ag-PfFt is virtually unaltered after $15 \mathrm{~min}$ of exposure to 80 and $90{ }^{\circ} \mathrm{C}$ (Figure 1D) due to the high thermostability of PfFt. Significantly, the Ag-PfFt sample exhibits excellent solubility at $0.5 \mathrm{mM}$ (200 mM in terms of $\mathrm{Ag}$ atoms) in water solution and high stability over a long period of time (long shelf life), evident from the absence of spectral changes in the $410 \mathrm{~nm}$ region after 8 months at $4{ }^{\circ} \mathrm{C}$. The high solubility and stability in water are two essential properties in the silver NPs field, as well as for a number of biomedical applications.

The AgNP-containing PfFt solutions were further characterized by transmission electron microscopy (TEM), analytical ultracentrifugation (AUC), and small-angle X-ray scattering (SAXS).

Transmission Electron Microscopy. TEM images of samples negatively stained with $2 \%$ phosphotungstic acid (PTA) to visualize the protein shell provided further evidence that the mineralization process does not perturb the overall protein structure and that the synthetic procedure leads to metal encapsulation within the protein cage (Figure 2). The fine structure of individual AgNPs was analyzed by high resolution TEM (HRTEM). The inset of Figure 2 shows clear lattice fringes with a linear pattern, indicating single-crystal formation. The calculated interplane distance is $2.4 \pm 0.2 \AA$ which closely corresponds to $\mathrm{Ag}(111)$. Significantly, the AgNP-containing PfFt molecules form an ordered array on the TEM grid (Figure 2 and Supporting Figure 3), in accordance with the strong tendency of ferritin and ferritin-like proteins to produce $2 \mathrm{D}$ and $3 \mathrm{D}$ crystals in vitro and in vivo ${ }^{42-44}$ and with the formation of

(42) Wolf, S. G.; Frenkiel, D.; Arad, T.; Finkel, S. E.; Kolter, R.; Minsky, A. Nature 1999, 400, 83.

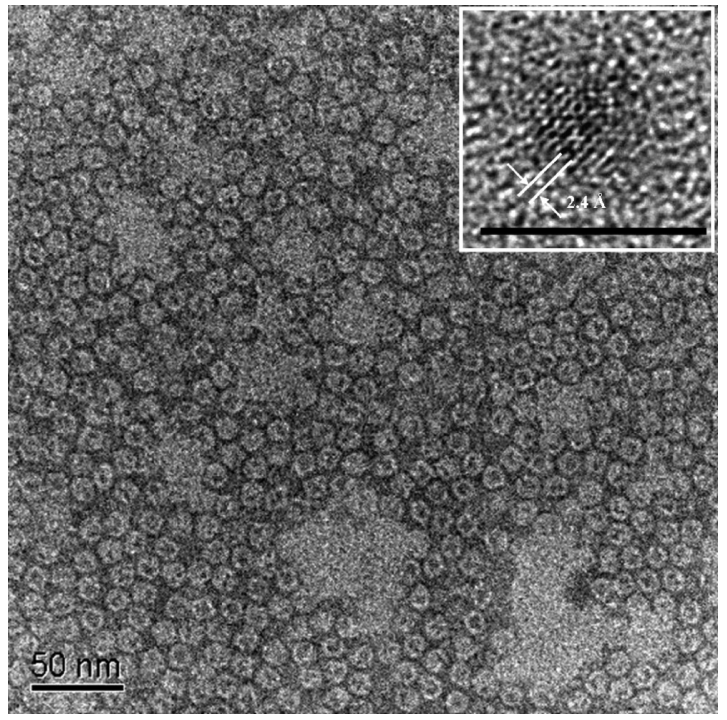

Figure 2. TEM image of AgNP-containing PfFt showing the metallic core surrounded by the ferritin shell (negative staining of the TEM grid with $2 \%$ PTA). Inset: HRTEM image of an unstained sample (scale bar: $5 \mathrm{~nm}$ ).

free-standing 3D crystals of magnetoferritin. ${ }^{45}$ This highly ordered arrangement makes AgNP-containing PfFt molecules ideal candidates for the preparation of metamaterials.

(43) Okuda, M.; Kobayashi, Y.; Suzuki, K.; Sonoda, K.; Kondoh, T.; Wagawa, A.; Kondo, A.; Yoshimura, H. Nano Lett. 2005, 5, 991.

(44) Ceci, P.; Chiancone, E.; Kasyutich, O.; Bellapadrona, G.; Castelli, L.; Fittipaldi, M.; Gatteschi, D.; Innocenti, C.; Sangregorio, C. Chem.-Eur. J. 2010, 16, 709. 


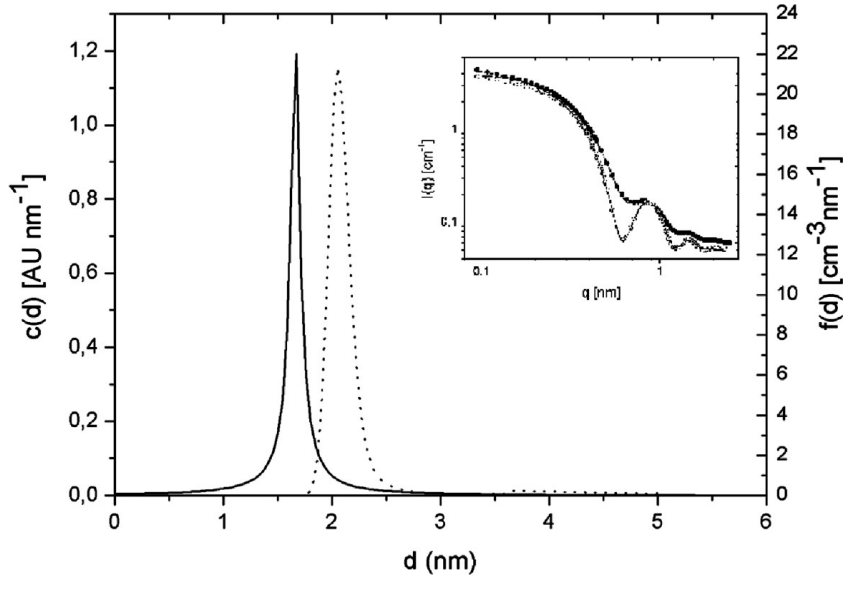

Figure 3. Particle size distribution of AgNPs encapsulated in PfFt. The dotted and solid lines were calculated from the AUC and SAXS data, respectively. Small-angle scattering curves of apoPfFt with $(O)$ and without (O) Ag particles are depicted in the inset. The symbols are the measured data (not all points are plotted), and the lines represent the fits.

Analytical Ultracentrifugation. AUC is a fractionating technique that allows determination of molar mass and particle size distribution with high statistical relevance as every particle contributes to the sedimentation profile. ${ }^{46}$ The particle size distribution was calculated with the program SEDFIT (provided by Dr. P. Schuck, National Institutes of Health) by taking into account the densities of the protein $\left(1.35 \mathrm{~g} / \mathrm{cm}^{3}\right)$ and of bulk silver particles $\left(10.5 \mathrm{~g} / \mathrm{cm}^{3}\right)$ and the thickness $(2 \mathrm{~nm})$ of the protein shell. ${ }^{47,48}$ The size distribution of the Ag-PfFt solution thus calculated has its maximum at $2.1 \mathrm{~nm}$ and a standard deviation of $0.4 \mathrm{~nm}$ (Figure 3), in agreement with the values obtained from the SAXS measurements (see below) and TEM study (not shown). Together with the high stability reported above, the high homogeneity of AgNPs encapsulated in PfFt shown by these studies is one of the required, as well as difficult to achieve, features of AgNPs for practical applications.

Small Angle X-ray Scattering. Small-angle scattering experiments were performed at the 7T-MPW-SAXS beamline (Berlin Helmholtz Centre for Materials and Energy, BESSY). The small-angle scattering curves were analyzed by fitting the experimental $I(q)$ curve (Figure 3 and Supporting Information) with a model based on the presence of monodispersed protein shells and polydispersed Ag particles attached to the shell wall inside the protein cavity. The inner and outer radii of the protein shell determined by SAXS measurements of apo-ferritin without the $\mathrm{Ag}$ load are $3.434 \pm 0.005 \mathrm{~nm}$ and $6.394 \pm 0.005 \mathrm{~nm}$, in good agreement with literature data. ${ }^{49}$ These values were used to reduce the fit parameters of the Ag-loaded samples. The differential Ag particle number density size distribution is shown in Figure 3. The particle diameter is $1.7 \pm 0.9 \mathrm{~nm}$. The number of particles is $(5 \pm 1) \times 10^{15} \mathrm{~cm}^{-3}$ which corresponds to $6 \pm$ $2 \mathrm{mg} / \mathrm{mL}$ of apoferritin filled with AgNPs. The values calculated from SAXS are comparable with the AUC data, although the mean diameter obtained is slightly smaller (Figure 3).

(45) Kasyutich, O.; Tatchev, D.; Hoell, A.; Ogrin, F.; Dewhurst, C.; Schwarzacher, W. J. Appl. Phys. 2009, 105, 07B528.

(46) Mächtle, W.; Börger, L. Analytical ultracentrifugation of polymers and nanoparticles; Springer: Berlin/Heidelberg, 2006.

(47) Jamison, J. A.; Krueger, K. M.; Yavuz, C. T.; Mayo, J. T.; LeCrone, D.; Redden, J. J.; Colvin, V. L. ACS Nano 2008, 2, 311.

(48) Goertz, V.; Dingenouts, N.; Nirschl, H. Part. Part. Syst. Charact. 2009, 26, 17.

(49) Bielig, H. J.; Kratky, O.; Rohns, G.; Wawra, H. Biochim. Biophys. Acta 1966, 112, 110.
X-ray Structure of $\mathbf{A g ( I ) - C o n t a i n i n g ~ P f F t . ~ T h e ~ c r y s t a l ~ s t r u c - ~}$ ture of PfFt loaded with $\mathrm{Ag}$ ions has been solved at $3.1 \AA$ resolution (Figure 4). In previous crystallization trials reported by a different research group ${ }^{35}$ that used a genetic-variant of human $\mathrm{H}$ ferritin as a template for $\mathrm{Ag}(\mathrm{I})$ incorporation, massive precipitation under crystallization conditions prevented protein crystallization. We speculate that the superior material stability and metal incorporation efficiency reported for PfFt with respect to the human HFt variant (95\% vs $27 \%$ ) was the major reason why crystallization of PfFt succeeded. The crystallographic data and refinements are reported in Table S1. The overall structure of Ag-PfFt is essentially the same as that of Ag-free PfFt. In contrast with previous reports using ferritin proteins from other species,${ }^{50}$ the addition of different metal ions such as $\mathrm{Cd}(\mathrm{II})$ or $\mathrm{Tb}(\mathrm{III})$ was not required for protein crystallization.

In Ag-containing PfFt, two different Ag binding/nucleation sites have been identified for the first time. Site I is fully occupied by silver, which is coordinated by Asp49 and His53, from one subunit, by Met170 from the C-terminus of the 2-fold symmetry-related one and by a water molecule hydrogen bounded to Glu130 (Figure 4, inset). Although site I is on the cavity surface close to the previously reported iron-binding site $\mathrm{C},{ }^{40}$ the silver atom is coordinated by different residues with respect to iron. In fact, site $\mathrm{C}$ iron is coordinated only by means of the carboxylates groups of Glu49, Glu126, Glu129, and Glu130. Interestingly, the involvement of Met170 in the formation of the silver binding site I results in an ordinate spatial arrangement of the whole C-terminus of the molecule. This allowed its structure to be determined for the first time, since in previously reported apo-PfFt and iron-containing PfFt structures the C-terminus was not visible due to disorder. ${ }^{40}$ The C-terminus of PfFt is longer than that in mammalian ferritins and crosses over the 2-fold axis, thereby hampering metal access to the 2-fold interface in the proximity of some of the mammalian ferritin nucleation sites, and possibly contributing to the reduced number of potential nucleation sites available inside the protein with respect to other ferritin molecules (Supporting Figure 6). It has been suggested before ${ }^{51}$ that the presence of a relatively small number of metal binding/ nucleation sites with respect to other ferritin proteins $(\sim 1.5 /$ subunit vs 5-8/subunit, Supporting Figures 2, 5) might be the basis of one of the most intriguing characteristics of PfFt, namely the narrow size distribution observed for the $\mathrm{Fe}_{3} \mathrm{O}_{4}{ }^{51}$ and $\mathrm{Ag}(0)$ nanoparticles incorporated inside the protein cage. In fact, each nucleation site has a characteristic structural environment, and nucleation events taking place at different sites might be affected by their particular architecture. A reduction in the number of nucleation sites implies an increase in the structural homogeneity of these sites and, possibly, of the nucleation events that they promote. Additionally, the lower the number of binding/ nucleation sites, the higher the probability that they are all filled at a given metal concentration, both within a single protein cavity and among the different proteins within the population. Conversely, the presence of a high number of sites is more likely to determine the existence of protein fractions filled to a different extent, thus broadening the size distribution of the nanoparticle.

(50) Harrison, P. M.; Artymiuk, P. J.; Ford, G. C.; Lawson, D. M.; Smith, J. M. A.; Treffry, A.; White, J. L. Biomineralization: Chemical and Biochemical Perspectives; Mann, S., Webb, J., Williams, R. J. P., Eds.; VCH: Weinheim, Germany, 1989; pp 257-294.

(51) Parker, M. J.; Allen, M.; Ramsay, B.; Klem, T. M.; Young, M. J.; Douglas, T. Chem. Mater. 2008, 20, 1541.

(52) Pymol; Delano Scientific LLC, San Carlos, LA (http://www.pymol.org). 
A

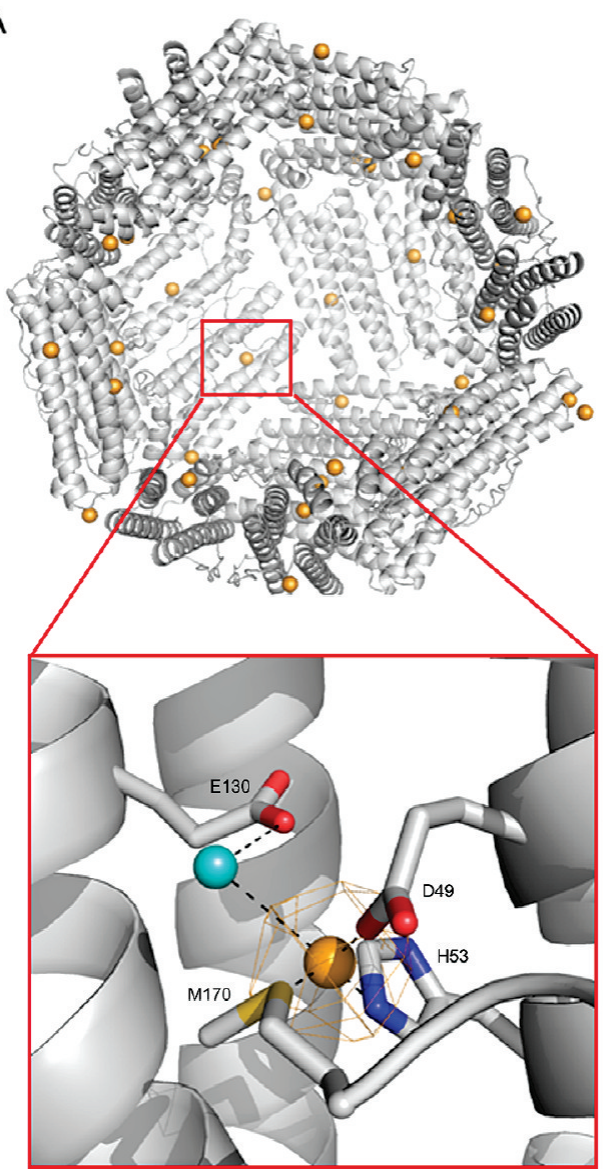

B

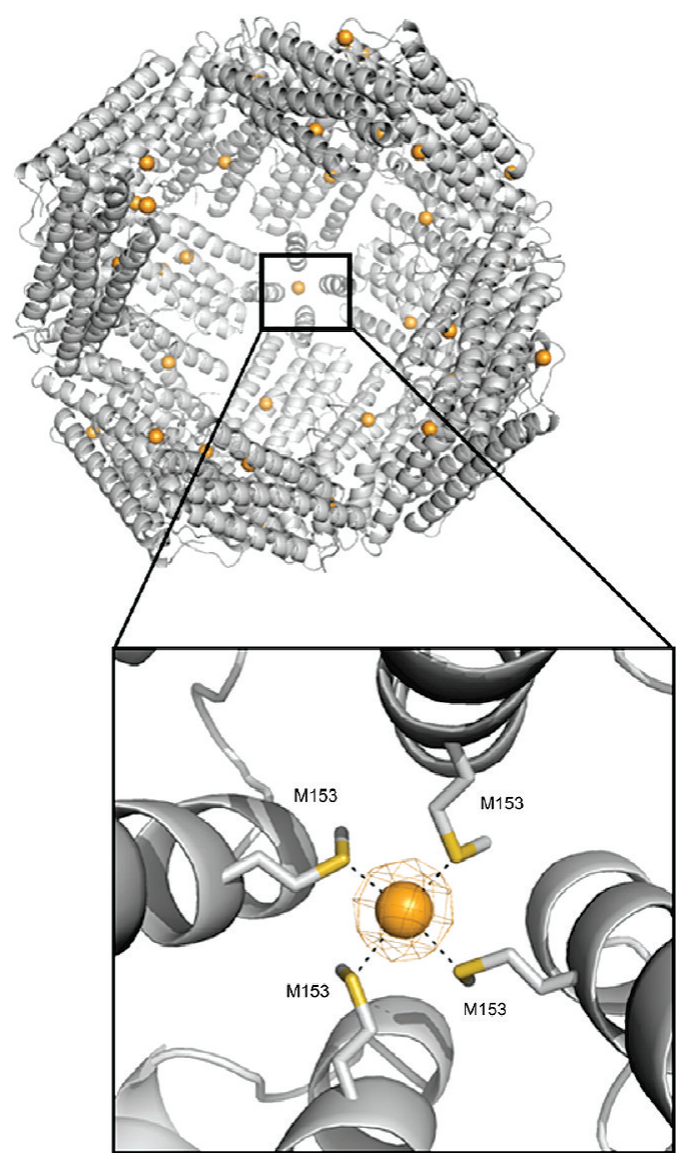

Figure 4. X-ray crystal structure of $\mathrm{Ag}(\mathrm{I})$-containing P. furiosus ferritin. View along the 3-fold (A) and 4-fold pores (B). Four chains were removed to display the internal cavity of the protein. The Ag binding/nucleation sites are shown as enlarged images of site I (left) and site II (right). The residues of the $\mathrm{Ag}(\mathrm{I})$ coordination shell are shown as sticks and colored according to atom-type: N, blue; O, red; S, yellow; C gray. Silver and water molecules are shown as spheres and depicted in orange and cyan, respectively.

Site II is located at the 4-fold pore, and the silver atom is coordinated by Met153 from four symmetry-related subunits (Figure 4, inset). This metal binding site has not been reported for any other metal-loaded ferritin protein, and therefore it is a peculiarity of PfFt (Supporting Figure 4). All the distance ranges between $\operatorname{Ag}(\mathrm{I})$ and the coordinating residues are reported in Table S2 (Supporting Information).

It is important to stress that the presence of methionine residues in metal binding/nucleation sites is also a peculiarity that differentiates PfFt with respect to all characterized ferritin proteins (Supporting Figure 4), suggesting that Met153 and Met170 might play a crucial role for efficient silver incorporation. This observation opens the road to the genetic engineering of other ferritin molecules, whose ability to function as efficient templates for the incorporation of AgNPs might be improved by the introduction of methionine residues at appropriate positions. This would be particularly desirable for in vivo diagnostic and therapeutic applications, for which the high efficiency of AgNPs formation displayed by PfFt could be joined to the low immunogenicity of human ferritins.

Iron and Silver Incorporation Experiments on $\operatorname{Ag}(0)$ - or Fe(III)-Containing PfFt Proteins. Iron incorporation experiments were carried out on $\operatorname{Ag}(0) \mathrm{NPs}$-containing PfFt samples to evaluate if the $\operatorname{Ag}(0)$ nanoclusters grown inside the protein cavity could inhibit binding/nucleation of iron atoms. Supporting Figure 7A shows that the addition of $400 \mathrm{Fe}(\mathrm{II})$ atoms to the $\mathrm{Ag}(0)$-containing PfFt sample results in negligible incorporation of the iron ions inside the protein cavity. This result, together with the SAXS analysis (Supporting Information), suggests that the Ag particles remain attached to the shell wall inside the protein cavity after the Ag reduction step, rather than becoming freely mobile in the cavity. Most likely the AgNPs, like the $\operatorname{Ag}(\mathrm{I})$ atoms in the crystal structure, are bound to the side chain sulfur atoms of the methionine residues in the nucleation sites.

Silver incorporation experiments were carried out on $\mathrm{PfFt}$ samples preincorporated with 24 or $48 \mathrm{Fe}(\mathrm{III})$. Both PfFt-24 and $48 \mathrm{Fe}$ (III) samples showed a substantial decrease in silver incorporation efficiency, whose extent was proportional to the amount of incorporated iron, i.e. $\sim 25$ and 50\% respectively (Supporting Figure 7B). Furthermore, the amount of Fe(III) inside the PfFt cavity was not affected by the addition of silver, as demonstrated by the ferrozine assay (Supporting Information).

These results indicate that the binding/nucleation sites of the silver and iron metals are, at least partially, overlapping, as suggested by X-ray structural analysis.

\section{Conclusions}

The data reported in this work demonstrate that small $(2.1 \pm$ $0.4 \mathrm{~nm}$ in diameter), homogeneous, and highly stable silver nanoparticles can be obtained in high yields and in a reproducible manner using ferritin from the hyperthermophile $P$. furious as a template for their controlled synthesis in water solution. Conversely, AgNPs could not be synthesized using other ferritins studied in parallel, namely human $\mathrm{H}$ and $\mathrm{L}$ ferritins, as protein 
cages. Importantly, the yields of AgNPs produced within $P$. furiosus ferritin were significantly higher than those previously reported using human $\mathrm{H}$ variants and horse spleen ferritin.

The results of this investigation are intriguing in that both they provide us with a deeper understanding of the biomineralization process, which is the necessary basis for the rational design of bioinspired inorganic materials, and because the produced AgNP-PfFt can be used as such for a number of applications in different areas.

Thanks to the first determination of the three-dimensional structure of an Ag-containing ferritin, the high efficiency and the narrow size distribution of the AgNPs could be ascribed to the peculiar external/internal charge distribution and, most importantly, to the small number of, and presence of methionine residues within, the silver binding/nucleation sites on the internal surface of PfFt.

The small size, high homogeneity, and great solubility in water of the AgNPs obtained in this work make them amenable to act as catalysts in environmentally friendly reactions, as already described for other ferritin-encapsulated metal NPs. ${ }^{28,31}$ The reported self-organization of AgNP-PfFt on TEM grids suggests that PfFt-enclosed AgNPs can be deposited on surfaces in an ordered fashion, a property that can be exploited in the preparation of metal nanoparticle array films and coatings.
Further, the protein cage can be chemically or genetically modified to target the silver nanoparticles to human pathogens and reduce their immunogenic potential, for example by PEGylation, thus increasing the selectivity and reducing the side effects of silver-based therapies. Finally, the use of a highly thermostable protein allows one to widen the accessible temperature range, an important issue for scale-up manufacturing and for industrial applications of nanomaterials.

Acknowledgment. The authors thank Prof. S. Costantini at the Istituto Superiore di Sanità of Rome for the GFAAS experiments, Dr. Lisa Karlsson at the Materials Department, University of Oxford for her help with HRTEM and BESSY Synchrotron Light Source, Berlin (Germany), where the X-ray data have been collected. P.C. and A.I. gratefully acknowledge Dr. Veronica Morea for critical reading of the manuscript. O.K. acknowledges EPSRC UK grant and EPSRC facilities access grant. This research was supported by the European Community's Seventh Framework Programme (FP7/ 2007-2013) under grant agreement no. 226716.

Supporting Information Available: Tables S1,S2; Figures $\mathrm{S} 1-\mathrm{S} 7$; and details on experimental procedures. This material is available free of charge via the Internet at http://pubs.acs.org.

JA910918B 